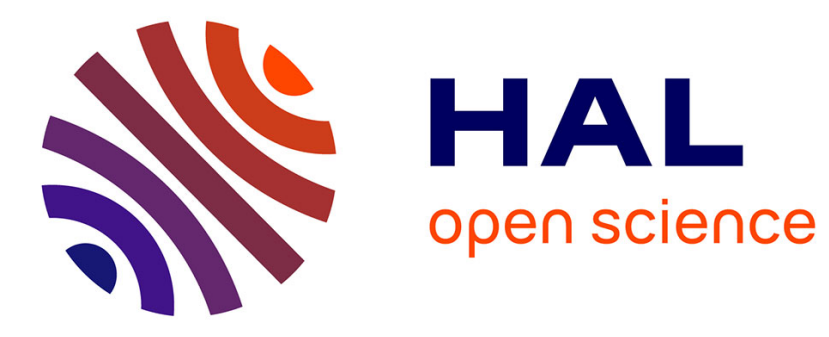

\title{
Regioselective functionalization of dimpled silica particles
}

Céline Hubert, Cyril Chomette, Pierre-Etienne Rouet, Antony Désert, Mona Tréguer-Delapierre, Jérôme Majimel, Stéphane Mornet, Adeline Perro, Etienne Duguet, Serge Ravaine

\section{To cite this version:}

Céline Hubert, Cyril Chomette, Pierre-Etienne Rouet, Antony Désert, Mona Tréguer-Delapierre, et al.. Regioselective functionalization of dimpled silica particles. Colloids and Surfaces A: Physicochemical and Engineering Aspects, 2016, 510, pp. 239-244. 10.1016/j.colsurfa.2016.05.089 . hal-01385231

\section{HAL Id: hal-01385231 \\ https://hal.science/hal-01385231}

Submitted on 2 Feb 2021

HAL is a multi-disciplinary open access archive for the deposit and dissemination of scientific research documents, whether they are published or not. The documents may come from teaching and research institutions in France or abroad, or from public or private research centers.
L'archive ouverte pluridisciplinaire HAL, est destinée au dépôt et à la diffusion de documents scientifiques de niveau recherche, publiés ou non, émanant des établissements d'enseignement et de recherche français ou étrangers, des laboratoires publics ou privés. 


\title{
Regioselective functionalization of dimpled silica particles
}

Céline Hubert ${ }^{a, b}$, Cyril Chomette ${ }^{c}$, Pierre-Etienne Rouet ${ }^{a, c}$, Antony Désert ${ }^{c}$, Mona TreguerDelapierre $^{c}$, Jérôme Majimel ${ }^{c}$, Stéphane Mornet ${ }^{c}$, Adeline Perro ${ }^{b}$, Etienne Duguet ${ }^{c}$, Serge Ravaine $^{a} *$

${ }^{a}$ CNRS, Univ. Bordeaux, CRPP, UPR 8641, F-33600 Pessac, France

Tel : (+33)-556845667 ; Fax: (+33)-556845600

E-mail: ravaine@ crpp-bordeaux.cnrs.fr

${ }^{\mathrm{b}}$ Univ. Bordeaux, CNRS, ISM, UMR 5255, F-33400 Talence, France

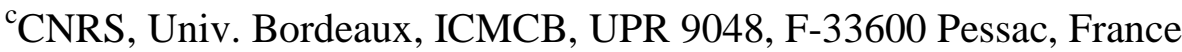

Keywords: surface modification ; regioselectivity; patchy particles ; silica; polystyrene

\begin{abstract}
Multipod-like particles made of a silica core surrounded by polystyrene nodules have been used as precursors to synthesize silica particles with 3 or 12 dimples through the selective growth of the dielectric core. Using the polymer nodules as temporary protecting masks, we regioselectively grafted amino groups onto the unprotected silica surface, as revealed by the adsorption of gold markers. After dissolution of the PS nodules, some polymer chains remained grafted onto the silica surface, forming organic bumps at the bottom of the dimples. These residues were also selectively functionalized, leading to silica particles with both entropic and enthalpic patches.
\end{abstract}




\section{Introduction}

The self-assembly of size-monodisperse isotropic colloidal particles to form colloidal crystals is one of the existing examples that justifies the analogy between atoms and hard spherical particles, that may be called colloidal atoms. Going one step further, one can consider the molecular world as a source of inspiration for designing colloidal analogues of simple molecules. Such colloidal molecules (CMs) are defined as robust discrete clusters of colloidal atoms. Many different strategies have been developed during the last decade to produce such “colloidal molecules" [1-5]. One approach is to start with preformed spherical particles and to control their aggregation into polyhedral clusters. Examples of this approach include colloidal aggregation on micro-patterned substrates [6] or in evaporating emulsions droplets [7]. Another strategy consists in nucleating and growing satellite particles on a preformed seed. We have recently reported the high-yield synthesis of binary polystyrene (PS)/silica multipods with a controlled morphology by a seeded-growth emulsion polymerization of styrene [8-11]. In this paper, we show that these multipod-like particles can be used as endotemplates to produce silica particles with 3 or 12 dimples. Using the PS pods as temporary masks [12], we regioselectively functionalized the unprotected silica surface. We also report that we are able to selectively functionalize the organic residues located at the bottom of the dimples that remain after the dissolution of the PS nodules. From a technological point of view, particles with heterogeneously patterned surfaces can offer a route to the production of target materials with specific (ordered as well as disordered) structures, thus being amenable in many technological applications.

\section{Materials and methods}

\subsection{Materials}


Tetraethoxysilane (TEOS, $\geq 99 \%$, Fluka), N-[3-(trimethoxysilyl)propyl]ethylenediamine (EDPS, 97\%, Aldrich), n-propyltriethoxysilane (PTES, 97\%, Aldrich), paraformaldehyde (reagent grade, crystalline, Sigma-Aldrich), tin(IV) chloride (98\%, Aldrich), ethylenediamine (99.5\%, Fluka), hydrochloric acid (37\%, Sigma-Aldrich) and ammonia (28-30\% in water, SDS) were used as received. Deionized water with a resistivity of $18.2 \mathrm{MOhm} . \mathrm{cm}$ at $25^{\circ} \mathrm{C}$ was obtained with a MilliQ system (Millipore). Tetrahydrofuran (THF), dimethylformamide (DMF), chloroform and absolute ethanol were purchased from Sigma-Aldrich.

\subsection{Methods}

2.2.1. Synthesis of dimpled silica particles. Multipods made of a central silica core and three, or twelve PS satellite nodules were prepared by seeded-growth emulsion polymerization of styrene, according to an already published procedure [8-9]. The regrowth of the silica cores was performed in the following conditions: a certain volume of TEOS, $\mathrm{V}_{\mathrm{TEOS}}$, was diluted ten times in absolute ethanol. The resulting solution was introduced continuously in a mixture made of $1 \mathrm{~mL}$ of an aqueous suspension of multipods, $45.5 \mathrm{~mL}$ of absolute ethanol and 3.2 $\mathrm{mL}$ of ammonia thanks to a single-syringe pump $\left(0.5 \mathrm{~mL} \cdot \mathrm{h}^{-1}\right)$. The mixture was stirred at room temperature during $12 \mathrm{~h}$. The dissolution of the PS nodules was performed in $100 \mathrm{~mL}$ of THF at room temperature under stirring for $1 \mathrm{~h}$. After washing by three cycles of centrifugation/redispersion in THF, the multivalent silica particles were finally redispersed in absolute ethanol.

2.2.2. Functionalization of the surface area between the dimples. To graft amino groups onto the unprotected silica surface, a given volume of EDPS corresponding to a nominal surface density of 20 functions.nm ${ }^{-2}$ was added directly into the particle suspension and the mixture was let to age at $40^{\circ} \mathrm{C}$ for 2 hours. The particle dispersion was purified by 3 cycles of centrifugation/redispersion in absolute ethanol. 5-nm gold nanoparticles, synthesized as previously described [13], were added into $20 \mathrm{~mL}$ of the functionalized multipod-like 
particles dispersion. The mixture was stirred at room temperature overnight, and then the particle assemblies were collected by centrifugation and washed three times with absolute ethanol. The dissolution of the PS nodules was performed in $100 \mathrm{~mL}$ of $\mathrm{THF}$ at room temperature under stirring for 1 hour. After washing by three cycles of centrifugation/redispersion in THF, the multivalent silica particles were finally redispersed in absolute ethanol.

2.2.3. Functionalization of the PS residues at the bottom of the dimples. To graft propyl groups onto the unprotected silica surface, a given volume of PTES corresponding to a nominal surface density of 20 functions.nm ${ }^{-2}$ was added dropwise into the particle suspension and the mixture was let to age at room temperature for $3 \mathrm{~h}$. The solvents were removed by using a rotavapor. An excess of THF was added to the solid residue to dissolve the PS nodules. After washing by three cycles of centrifugation/redispersion in THF, the silica particles were redispersed in chloroform. Finally, the particles were washed by three cycles of centrifugation/redispersion in $40 \mathrm{~mL}$ of chloroform. The chloromethylation of the PS chains was done by adding $5 \mathrm{~mL}$ of a $3 \mathrm{M}$ butyl chloromethylether solution in chloroform, prepared according to Warshawsky et al. [14], and $0.3 \mathrm{~mL}$ of $\mathrm{SnCl}_{4}$ into $20 \mathrm{~mL}$ to the silica particles and the mixture was aged overnight at $45^{\circ} \mathrm{C}$. After washing by three cycles of centrifugation/redispersion in $\mathrm{HCl}$ solution (4 wt.\% in water) and three cycles of centrifugation/redispersion in a water/EtOH (50/50 wt \%), the silica particles were redispersed in $20 \mathrm{~mL}$ of DMF. Then, $1 \mathrm{~mL}$ of ethylenediamine was added and the mixture was aged overnight at $90^{\circ} \mathrm{C}$. After three cycles of centrifugation/redispersion in water, the $\mathrm{pH}$ was adjusted to 4 with $\mathrm{HCl}$. Finally, 5-nm gold nanoparticles were added into the suspension. The mixture was stirred at room temperature overnight, and then the particle assemblies were collected by centrifugation and washed three times with absolute ethanol. 


\subsubsection{Characterization techniques. Electron microscopy experiments and statistical}

calculations. TEM images were obtained with a Hitachi H600 microscope operating at $75 \mathrm{kV}$ and with a Hitachi H7650 operating at $120 \mathrm{kV}$. Typically, the collected samples were diluted 100 times in ethanol and one drop was deposited on a copper grid coated with a carbon membrane. Statistical analyses of the cluster morphology were performed on a minimum of 100 clusters per batch.

\section{Results}

\subsection{Synthesis of the tripod- and dodecapod-like particles}

We have already described the seeded-growth emulsion polymerization of styrene in the presence of silica [8-9, 15-19]. When the surface of the silica seeds is treated by a compatibilizer, e.g. methacryloxymethyltriethoxysilane (MMS), some organophilic loci promoting the surface capture of the growing macromolecules are created. Therefore the nucleation/growth of the PS nodules occurs preferentially onto the surface of the seeds. As previously shown, using the optimal nominal surface density of MMS onto the silica seeds, i.e.

0.5 fct.nm ${ }^{-2}$, we observed the preferential surface nucleation and growth of a limited number of PS nodules per seed. We also reported that the size of the silica seeds, $D_{\text {silica }}$, influences the final number of PS nodules per seed, $N_{P S / \text { silica }}^{\infty}$, as it conditions the maximal number of satellites which can co-exist on the same seed for steric reasons. For instance, when the fraction of sodium dodecyl sulfate (SDS) was equal to $5 \mathrm{wt} . \%$, tetrapods and hexapods were obtained with morphology yield over $80 \%$ from $55-\mathrm{nm}$ and $85-\mathrm{nm}$ silica seeds, respectively (Figures 1a and 1c and Table 1, Entries \#1.2 and \#1.3) [9].

In order to get clusters with a small number of PS satellites, e.g. tripods, as the main population, we explored a route by rendering the nucleation process less favorable to decrease 
the number of initial nuclei per seed $N_{P S / s i l i c a}^{0}$. Assuming that the higher the SDS fraction in the surfactant mixture, the smaller and the more numerous the PS particles, we performed an experiment with 55-nm silica seeds by decreasing the fraction of SDS from 5 to $1 \mathrm{wt} . \%$ (Table 1, Entry \#1.1). The statistical analysis of the TEM images showed that the distribution morphology was dramatically narrowed with essentially tripods $(70 \%)$ (Figure $1 \mathrm{~b})$.

Another challenge was to produce already-observed clusters but for a different seed size. For instance, we attempted the synthesis of dodecapods from $85-\mathrm{nm}$ silica seeds, while these multipods were previously obtained with 255-nm seeds when no SDS was used [8]. We first performed an experiment by increasing the fraction of SDS from 5 to $10 \mathrm{wt} . \%$ but a complex mixture with mostly octopods $(38 \%)$ and "multi-silica" clusters $(26 \%)$ was obtained. We thus developed another strategy to increase the $N_{P S / \text { silica }}^{0}$ value by lowering the monomer concentration, i.e. increasing the surfactant-to-monomer ratio. An experiment was performed by decreasing the styrene concentration from 100 to 45 g. $\mathrm{L}^{-1}$ and dodecapods were indeed readily obtained with a yield of $74 \%$ (Table 1, Entry \#1.4, and Figure 1d).

Table 1. Influence of the SDS fraction in the surfactant mixture and of the styrene concentration on the morphology and geometrical parameters of the PS/silica clusters $\left(\left[\mathrm{Na}_{2} \mathrm{~S}_{2} \mathrm{O}_{8}\right]_{0}=0.5 \mathrm{~g} . \mathrm{L}^{-1} ; \quad\right.$ surfactant $\left.]=3 \mathrm{~g} \cdot \mathrm{L}^{-1}\right)$. Bold numerals concern the main cluster population.

\begin{tabular}{|c|c|c|c|c|c|}
\hline \multicolumn{2}{|l|}{ Entry } & $\# 1.1$ & $\# 1.2$ & $\# 1.3$ & $\# 1.4$ \\
\hline \multirow{6}{*}{ Experimental conditions } & $D_{\text {silica }}(\mathrm{nm})$ & 55 & 55 & 85 & 85 \\
\hline & $N_{\text {silica }}\left(10^{15} \mathrm{~L}^{-1}\right)$ & 19 & 18 & 7.3 & 7.3 \\
\hline & $S_{\text {silica }}\left(\mathrm{m}^{2} \cdot \mathrm{L}^{-1}\right)$ & 174 & 171 & 166 & 166 \\
\hline & {$[\text { styrene }]_{0}\left(\mathrm{~g} . \mathrm{L}^{-1}\right)$} & 100 & 100 & 100 & 45 \\
\hline & wt. $\%$ of SDS & 1 & 5 & 5 & 5 \\
\hline & Conversion $(\%)$ & 90 & 89 & 92 & 89 \\
\hline \multirow{5}{*}{$\begin{array}{l}\text { Final batch composition in } \\
\text { clusters }^{\mathrm{a}}\end{array}$} & $\%$ mono/bipods & 17 & 2 & - & - \\
\hline & $\%$ tripods & 70 & 11 & - & - \\
\hline & $\%$ tetrapods & 2 & 84 & 3 & - \\
\hline & $\%$ pentapods & - & - & 13 & \multirow{2}{*}{\}$_{4}$} \\
\hline & $\%$ hexapods & - & - & 83 & \\
\hline
\end{tabular}




\begin{tabular}{|c|c|c|c|c|c|}
\hline \multirow{5}{*}{} & $\%$ heptapods & - & - & - & - \\
\cline { 2 - 6 } & $\%$ octopods & - & - & - & 5 \\
\cline { 2 - 6 } & $\%$ nonapods & - & - & - & 5 \\
\hline & $\%$ decapods & - & - & - & 5 \\
\cline { 2 - 6 } & $\%$ hendecapods & - & - & - & $\mathbf{7 4}$ \\
\cline { 2 - 6 } & $\%$ dodecapods & - & - & - & 1 \\
\hline & $\%$ "multi-silica" & 11 & - & 1 & 83 \\
\hline
\end{tabular}

${ }^{\mathrm{a}}$ as extracted from the statistical analysis of TEM images

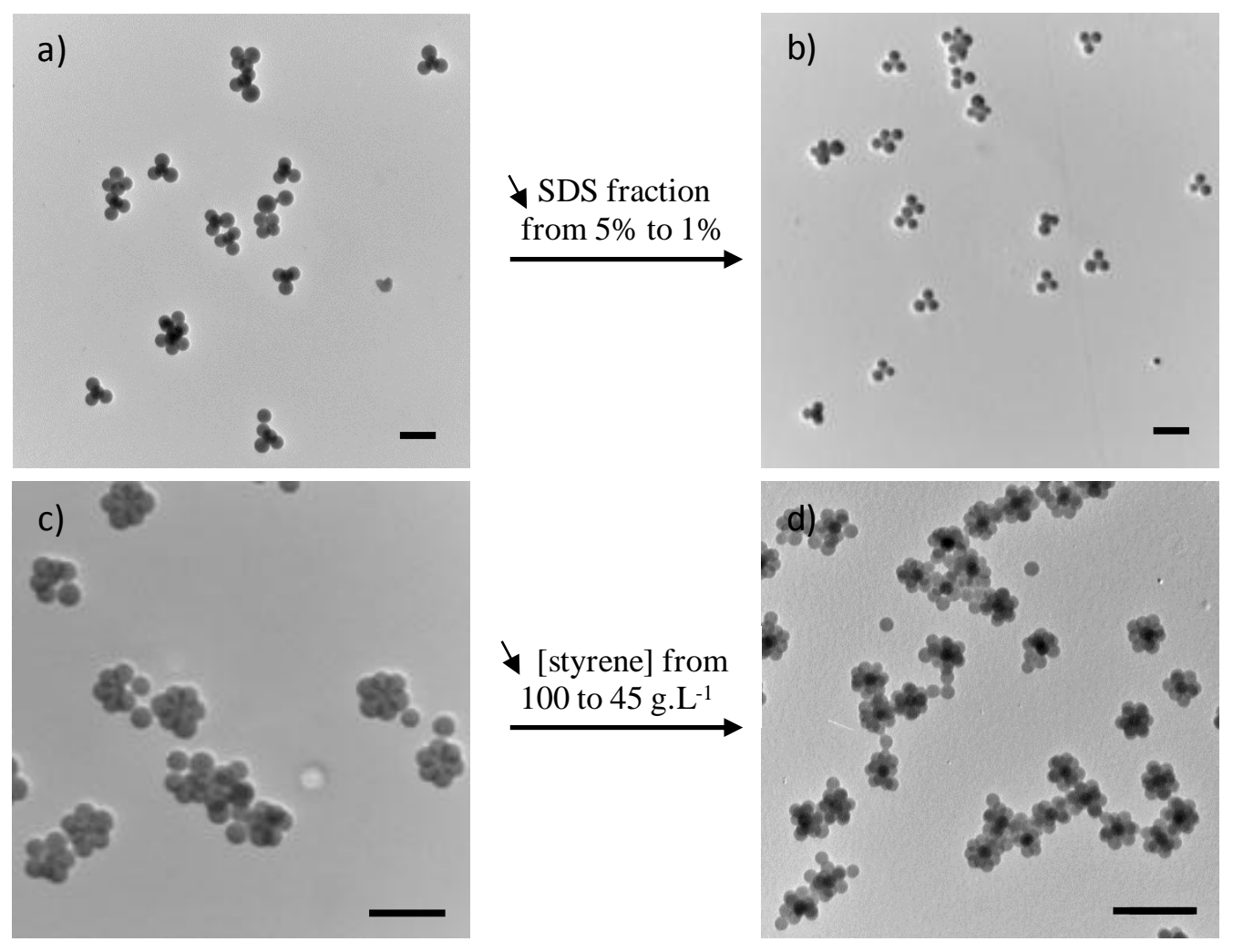

Figure 1. Typical TEM images of multipods obtained by styrene emulsion polymerization from silica seeds in different experimental conditions described in Table 1: (a) Tetrapods, Entry \#1.2; (b) Tripods, Entry \#1.1; (c) Hexapods, Entry \#1.3; (d) Dodecapods, Entry \#1.4. Scale bars: $500 \mathrm{~nm}$. 


\subsection{Dimpled particles}

We have already shown [10] that (i) the slow addition of a dilute solution of tetraethoxysilane in ethanol into a hydroalcoholic suspension of multipods, in presence of ammonia, led to the growth of the silica core conforming to the shape of the polystyrene nodules, (ii) the subsequent dissolution of the PS nodules gave rise to silica particles with a fixed number of dimples. We studied the influence of the quantity of silica precursor by running a series of experiments during which $100 \mu \mathrm{L}, 200 \mu \mathrm{L}$ or $300 \mu \mathrm{L}$ of TEOS were added to a suspension of dodecapods. As shown in Figure 2, the size of the dimpled silica particles increases with

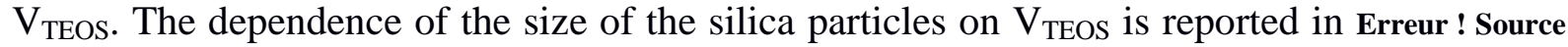
du renvoi introuvable.
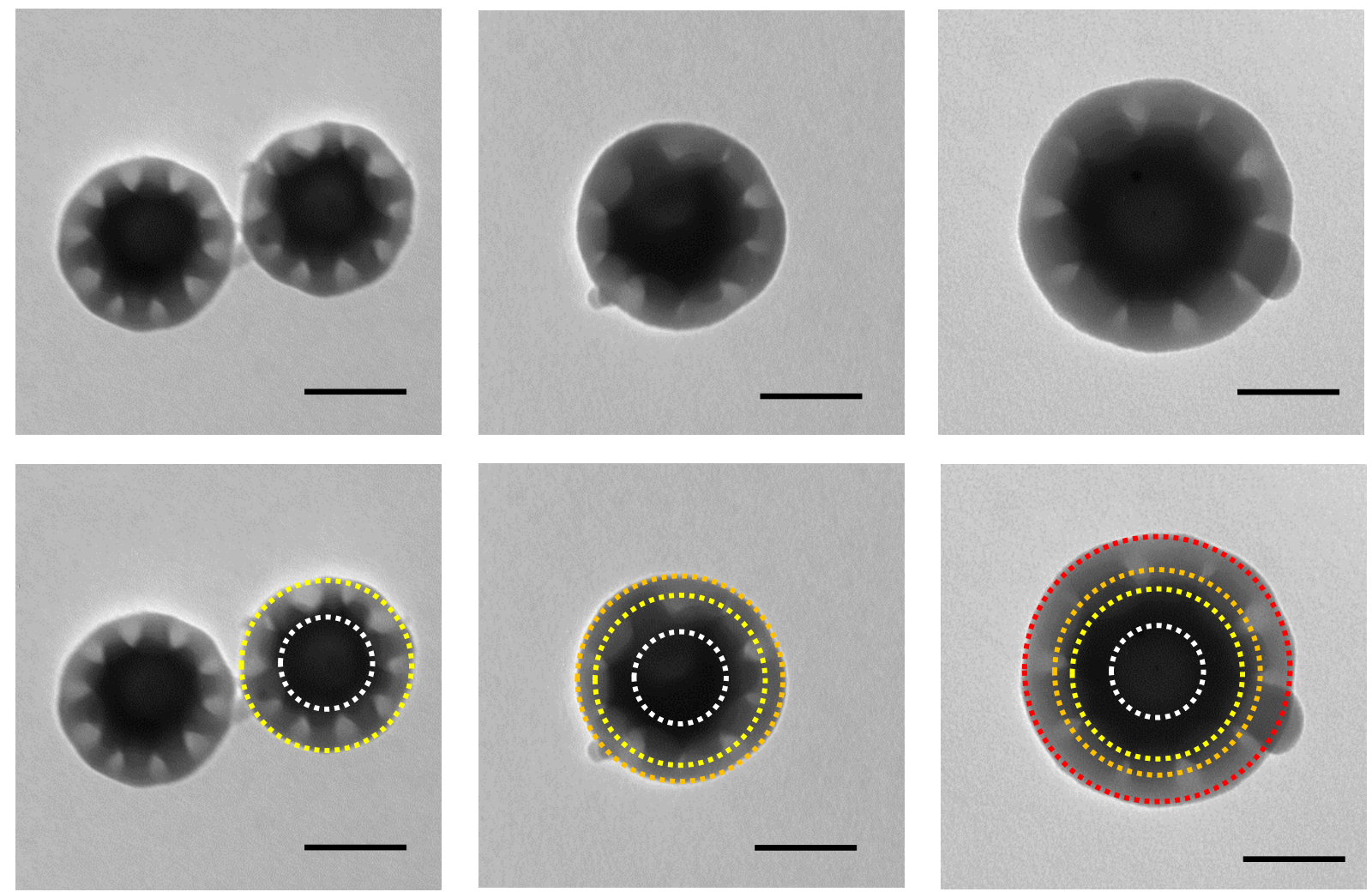

Figure 2. TEM images of silica particles with 12 dimples obtained after the addition of: $\mathrm{V}_{\mathrm{TEOS}}=100 \mu \mathrm{L}, 200 \mu \mathrm{L}$ and $300 \mu \mathrm{L}$ (from left to right). Scale bars: $100 \mathrm{~nm}$. On the bottom row, the white dotted circle represents the initial $85-\mathrm{nm}$ silica seed and the yellow, orange and red dotted circles illustrate the sizes of the particles after the addition of the different amounts of TEOS. 


\begin{tabular}{cccc}
\cline { 2 - 4 } & $\mathrm{V}_{\text {TEOS }}=\mathbf{1 0 0 \mu \mathrm { L }}$ & $\mathrm{V}_{\text {TEOS }}=\mathbf{2 0 0 \mu \mathrm { L }}$ & $\mathrm{V}_{\text {TEOS }}=\mathbf{3 0 0 \mu \mathrm { L }}$ \\
\hline $\begin{array}{c}\text { Average diameter values } \\
\text { of the silica particles }(\mathrm{nm})\end{array}$ & 170 & 205 & 255 \\
\hline
\end{tabular}

Table 2. Average diameter values of the silica particles with 12 dimples after the injection of various volumes of TEOS and dissolution of the PS nodules using THF.

\subsection{Regioselective functionalization}

In order to regioselectively functionalize the surface of the silica particles, we first used the PS nodules as temporary protecting masks (Figure 3, route A). We added EDPS at the end of the TEOS condensation to graft amino groups onto the unprotected silica surface. We then mixed the functionalized multipods with an aqueous suspension of THPC-stabilized 5-nm gold nanoparticles [13], which are known to adsorb specifically on amine groups. After the dissolution of the PS nodules, Figure 4a-b shows that the gold nanoparticles packed densely on the amine-modified silica surface, whereas no gold nanoparticles was visible on the nonmodified surface of the concave faces of the silica particles, indicating highly selective functionalization.

We also took benefit of the fact that the PS chains which are covalently bonded to the silica surface thanks to the copolymerization of the methacrylate groups of the MMS grafts with styrene remain at the bottom of the dimples after the dissolution of the PS nodules [20]. Indeed, the dissolution of the PS nodules by THF molecules consisted in the disentanglement of the chains and especially from those which remained covalently bonded to the silica surface. Therefore, the structure of the dimpled silica particles was more complex than initially expected: to their complex shapes shall be added their biphasic nature. The silica dimples can be considered as entropic patches as well as potential enthalpic ones due to the discrepancy in term of chemical reactivity exhibited by the silica from one side and the 
residual PS chains on the other side. We selectively modified the residual PS chains located at the bottom of the dimples through a chloromethylation reaction of their phenyl groups (see inset of Figure 4c) and the subsequent grafting of ethylenediamine molecules onto the chloromethylated macromolecules (Figure 3, route B). Here again, this regioselective functionalization was revealed by the specific adsorption of gold nanoparticles within the dimples (Figure 4c-d).

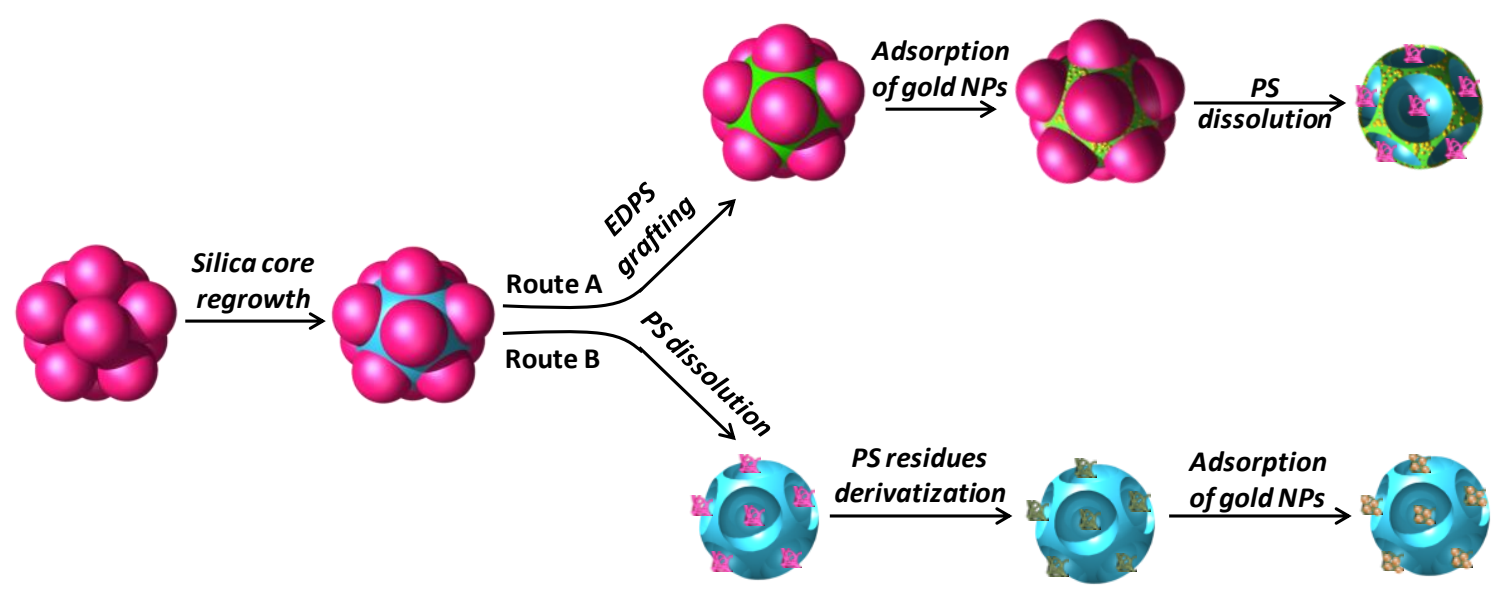

Figure 3. Schematic representation of the regioselective functionalization of dimpled silica particles. 

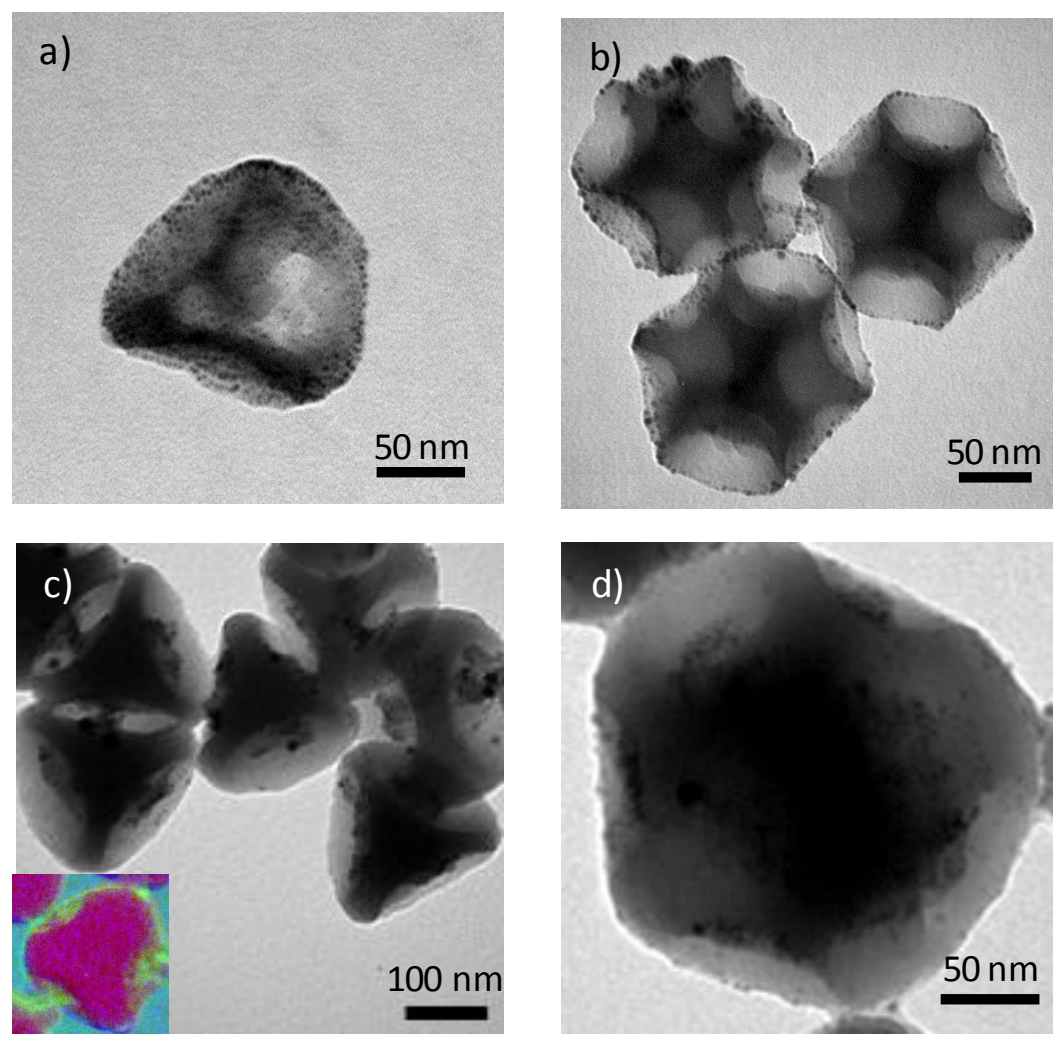

Figure 4. Top row: TEM images of the gold-decorated dimpled silica particles after the dissolution of the polystyrene nodules. Bottom row: TEM images of silica particles with c) 3 , d) 12 gold-decorated bumps at the bottom of the dimples. The inset shows an Electron energy loss spectroscopy (EELS) mapping after chloromethylation of the residual PS chains (Silicon in red, Carbon in blue and Chlorine in green).

\section{Conclusion}

In summary, we synthesized tripods and dodecapods by modifying the SDS fraction in the surfactant mixture and of the styrene concentration during the emulsion polymerization in the presence of silica seeds. Silica particles with 3 or 12 dimples were synthesized through the growth of the silica core of the corresponding binary PS/silica multipods and the subsequent dissolution of the PS nodules. The size of these new dimpled silica particles can be easily controlled by adjusting the volume of the injected TEOS solution. We also demonstrated the successful functionalization of both the non-protected surface of the grown silica core and of the organic residues remaining at the bottom of each dimple, thereby providing the possibility of getting particles with patches combining both enthalpic and entropic characters. These 
particles are promising building blocks for the fabrication of new lattices by self-assembly or as "lock" particles able to be combined with a precise number of "key" particles in each dimple in order to obtain new supracolloids [21-23].

\section{Acknowledgements}

TEM experiments were performed at the Plateforme de Caractérisation des Matériaux and Bordeaux Imaging Center of the University of Bordeaux. This work was supported by the Conseil Régional d'Aquitaine, the Agence Nationale de la Recherche (grant ANR-07-BLAN0271), the LabEx AMADEus (ANR-10-LABX-42) and the IdEx Bordeaux (ANR-10-IDEX03-02), i.e. the Investissements d'Avenir programme of the French government managed by the Agence Nationale de la Recherche.

\section{References}

[1] A. van Blaaderen, Chemistry: Colloidal molecules and beyond, Science 301 (2003) $470-471$.

[2] G.-R. Yi, V.N. Manoharan, S. Klein, K.R. Brzezinska, D.J. Pine, F.F. Lange, S.-M. Yang, Monodisperse micrometer-scale spherical assemblies of polymer particles, Adv. Mater. 14 (2002) 1137-1140.

[3] D. Zerrouki, B. Rotenberg, S. Abramson, J. Baudry, C. Goubault, F. Leal-Calderon, D.J. Pine, J. Bibette, Preparation of doublet, triangular, and tetrahedral colloidal clusters by controlled emulsification, Langmuir 22 (2006) 57-62.

[4] W. Stöber, A. Berner, R. Blaschke, The aerodynamic diameter of aggregates of uniform spheres, J. Coll. Int. Sci. 29 (1969) 710-719. 
[5] E. Duguet, A. Désert, A. Perro, S. Ravaine, Design and elaboration of colloidal molecules: an overview, Chem. Soc. Rev. 40 (2011) 941-960.

[6] Y. Masuda, T. Itoh, K. Koumoto, Self-assembly and micropatterning of sphericalparticle assemblies, Adv. Mater. 17 (2005) 841-845.

[7] V.N. Manoharan, M.T. Elsesser, D.J. Pine, Dense packing and symmetry in small clusters of microspheres ,Science 301 (2003) 483-487.

[8] A. Perro, E. Duguet, O. Lambert, J.-C. Taveau, E. Bourgeat-Lami, S. Ravaine, A chemical synthetic route towards "colloidal molecules", Angew. Chem. Int. Ed. 48 (2009) $361-365$

[9] A. Désert, I. Chaduc, S. Fouilloux, J.-C. Taveau, O. Lambert, M. Lansalot, E. Bourgeat-Lami, A. Thill, O. Spalla, S. Ravaine, E. Duguet, High-yield preparation of polystyrene/silica clusters of controlled morphology, Polym. Chem. 3 (2012) 1130-1132.

[10] A. Désert, C. Hubert, Z. Fu, L. Moulet, J. Majimel, P. Barboteau, A. Thill, M. Lansalot, E. Bourgeat-Lami, E. Duguet, S. Ravaine, Synthesis and site-specific functionalization of tetravalent, hexavalent, and dodecavalent silica particle, Angew. Chem. Int. Ed. 52 (2013) 11068-11072.

[11] A. Désert, J. Morele, J.-C. Taveau, O. Lambert, M. Lansalot, E. Bourgeat-Lami, A. Thill, O. Spalla, L. Belloni, S. Ravaine, E. Duguet., Multipod-like silica/polystyrene clusters, Nanoscale, DOI: 10.1039/c5nr07613g.

[12] A. Perro, S. Reculusa, F. Pereira, M.-H. Delville, C. Mingotaud, E. Duguet, E. Bourgeat-Lami, S. Ravaine, Towards large amounts of Janus nanoparticles through a protection-deprotection route, Chem. Commun. (2005) 5542-5543.

[13] D.G. Duff, A. Baiker, P.P. Edwards, A new hydrosol of gold clusters, Chem. Commun. (1993) 96-98.

[14] A. Warshawsky, A. Deshe, Halomethyl octyl ethers: Convenient halomethylation reagents, J. Polym. Sci. Polym. Chem. Ed. 23 (1985) 1839-1841. 
[15] J.C. Taveau, D. Nguyen, A. Perro, S. Ravaine, E. Duguet, O. Lambert, New insights into the nucleation and growth of PS nodules on silica nanoparticles by 3D cryo-electron tomography, Soft Matter 4 (2008) 311-315.

[16] S. Reculusa, C. Poncet-Legrand, A. Perro, E. Duguet, E. Bourgeat-Lami, C. Mingotaud, S. Ravaine, Hybrid dissymmetrical colloidal particles, Chem. Mater. 17 (2005) 3338-3344.

[17] A. Perro, D. Nguyen, S. Ravaine, E. Bourgeat-Lami, O. Lambert, J.C. Taveau, E. Duguet, Planar submicronic silica-polystyrene particles obtained by substrate-directed shaping, J. Mater. Chem. 19 (2009) 4225-4230.

[18] I. Chaduc, J. Parvole, T. Doussineau, R. Antoine, A. Désert, P.Y. Dugas, S. Ravaine, E. Duguet, E. Bourgeat-Lami, M. Lansalot, Towards a one-step method for preparing silica/polymer heterodimers and dimpled polymer particles, Polymer 70 (2015) 118-126.

[19] E. Bourgeat-Lami, M. Insulaire, S. Reculusa, A. Perro, S. Ravaine, E. Duguet, Nucleation of polystyrene latex particles in the presence of gammamethacryloxypropyltrimethoxysilane: functionalized silica particles., J. Nanosci. Nanotech. 6 (2006) 432-444.

[20] C. Hubert, C. Chomette, A. Désert, M. Sun, M. Treguer-Delapierre, S. Mornet, A. Perro, E. Duguet, S. Ravaine, Synthesis of multivalent silica nanoparticles combining both enthalpic and entropic patchiness, Faraday Discuss. 181 (2015) 139-146.

[21] S. Sacanna, W.T.M. Irvine, P.M. Chaikin, D.J. Pine, Lock and key colloids, Nature 464 (2010) 575-578.

[22] S. Sacanna, D.J. Pine, G.-R. Yi, Engineering shape: the novel geometries of colloidal self-assembly, Soft Matter 9 (2013) 8096-8106.

[23] Y. Wang, Y. Wang, X. Zheng, G.-R. Yi, S. Sacanna, D.J. Pine, M. Weck, Threedimensional lock and key colloids, J. Am. Chem. Soc. 136 (2014) 6866-6869. 